\title{
Exploring new paradigms in mental health and capacity law: persons, populations, and parity of esteem \\ JOHN COGGON* AND JUdy LAING*
}

Centre for Health, Law, and Society, University of Bristol Law School

\begin{abstract}
This paper examines key contemporary policy and legal agendas regarding mental health, with a view to bighlighting contributions that may be brought from new and emerging discourses in academic health law. In particular, it does so from the perspective of the related fields of public health law and human rights law. Whilst core definitions of public health speak to questions regarding mental health and well-being, recent reports from a range of professional and advocacy organisations urge the message that mental health remains a neglected area of concern. This has led to an emphasis on the field of public mental health as a discrete area of study, policy and practice. We argue and explain how the related field of public mental health law should be conceptualised and operationalised. This entails an examination of the fundamental requirement of law to support and promote good mental health, with a renewed focus on prevention and proactive intervention rather than reactive measures. We suggest that a framing made by reference to human rights models will support the combined ethical and practical commitments that must be met by public mental health law.
\end{abstract}

Keywords: mental health; public health; law; human rights; health inequalities; parity of esteem.

\section{Introduction}

$\mathrm{M}$ ental disorders are among the most prevalent diseases worldwide. ${ }^{1}$ Recent figures on the scale of mental ill health are staggering. The World Health Organization (WHO) has estimated that mental health problems account for more disability-adjusted life years lost than cancer or cardiovascular disease. ${ }^{2}$ Depression is the predominant mental health

* Professor of Law; Co-Director, Centre for Health, Law, and Society, University of Bristol Law School, UK; Honorary Member, UK Faculty of Public Health; john.coggon@bristol.ac.uk

** Professor of Mental Health Law, Rights and Policy; Co-Director, Centre for Health, Law, and Society, University of Bristol Law School, UK; j.m.laing@bristol.ac.uk. We would like to express our strong gratitude to colleagues for feedback on an earlier version of this paper at the launch event of the Centre for Health, Law, and Society (CHLS) in Bristol in October 2017, and to participants at the CHLS roundtable on 'Public Mental Health Law' in April 2018. We are also extremely grateful to the two reviewers of the paper for their detailed and insightful comments on an earlier draft.

1 Theo Vos et al, 'Global, Regional, and National Incidence, Prevalence, and Years Lived with Disability for 301 Acute and Chronic Diseases and Injuries in 188 Countries, 1990-2013: A Systematic Analysis for the Global Burden of Disease study' (2013) The Lancet 386:9995, 743-800.

2 Located at WHO, Mental Disorder and Substance Use <www.who.int/gho/publications/mdgs-sdgs/MDGsSDGs2015_chapter7.pdf?ua=1>. 
problem, followed by anxiety, schizophrenia, and bipolar disorder. ${ }^{3}$ Huge rises are anticipated in the number of people with dementia and Alzhemier's disease over the next 20-30 years, linked to the rapidly ageing world population. Mental ill health is now regarded as a major public and global health issue. ${ }^{4}$

In the UK, the figures are equally startling. The most recent Adult Psychiatric Morbidity Survey of Mental Health and Wellbeing revealed that almost one in five people in England aged 16 and over showed symptoms of anxiety or depression, and nearly half of adults (43.4\%) believe that they have had a diagnosable mental health condition at some point in their life. ${ }^{5}$ There are indications that the incidence of mental ill health has been rising steadily over the last two decades, especially in women. ${ }^{6}$ This may be due to people being more willing to report and admit to having a mental health problem, but environmental, social and economic conditions are key contributing factors to the increase in many conditions. ${ }^{7}$

In spite of vast evidence on the prevalence and disabling impact of mental ill health, and although there has been progress in some countries, the WHO's Mental Health Atlas 2017 reveals that there is a global shortage of workers trained in mental health and a lack of investment in mental health planning, programmes and services. ${ }^{8}$ This is bolstered by data from a range of other sources. For example, treatment provision for depression globally is low, and surveys indicate that less than half of people living with depression receive any treatment. ${ }^{9}$ There are significant challenges which have led to a huge 'treatment gap' between physical and mental ill health, where up to 9 out of 10 people across the world do not receive even basic mental healthcare in some countries. It is clear that, on a global scale, mental health continues to be neglected, and investment in crucial services is not happening quickly enough. Failure to invest in mental health has personal, social and economic costs on a vast scale. ${ }^{10}$

Moreover, relevant regulatory frameworks in many countries are highly reactive and ineffective in promoting access to timely or universal mental healthcare or treatment, less still in positively promoting conditions for good mental health and well-being. The Atlas indicates that less than half of member states' domestic mental health laws and policies

3 Ibid.

4 Ibid. See also WHO/Alzheimer's International, Dementia: A Public Health Priority (World Health Organization 2012) <www.who.int/mental_health/publications/dementia_report_2012/en>.

5 The survey takes place every seven years and the latest version was published in September 2016 $<$ https://digital.nhs.uk/data-and-information/publications/statistical/adult-psychiatric-morbidity-survey $>$. See also Mental Health Foundation, Fundamental Facts about Mental Health 2016 <www.mentalhealth.org.uk/publications/fundamental-facts-about-mental-health-2016>.

6 Adult Psychiatric Morbidity Survey of Mental Health and Wellbeing, England, 2014 (National Statistics 2016) 5. For example, the Psychiatric Morbidity Surveys in England show a 15\% increase (from 24\% in 2007 to $39 \%$ in 2014) of adults aged 16-74 with conditions such as anxiety or depression accessing mental health treatment. See <https://digital.nhs.uk/data-and-information/publications/statistical/adult-psychiatric-morbiditysurvey $>$.

7 Ibid. See also John Coggon, 'Depression and Public Health Law: Ethics, Governance, and the Socio-Political Determinants of Health and Well-being' in Charles Foster and Jonathan Herring (eds), Depression: Law and Ethics (Oxford University Press 2017); 'What is Depression and Why is it Rising?', The Guardian (London, 2 June 2018) <www.theguardian.com/news/2018/jun/04/what-is-depression-and-why-is-it-rising>.

8 See <www.who.int/mental_health/evidence/atlas/mental_health_atlas_2017/en>.

9 Philip S Wang et al, 'Use of Mental Health Services for Anxiety, Mood, and Substance Disorders in 17 Countries in the WHO World Mental Health Surveys' (2007) The Lancet 370:9590, 841-50.

10 Dr Shekhar Saxena, Director of WHO's Department of Mental Health and Substance Abuse. See <www.who.int/mental_health/evidence/atlas/atlas_2017_web_note/en>. 
comply fully with relevant international human rights standards. ${ }^{11}$ Unsurprisingly, these deficiencies have been described as a 'failure of humanity' and led to some of the worst human rights abuses in the history of global health. ${ }^{12}$ An appreciation of this global context is essential to underline that there are key rights in need of protection, many of which are shaped by social and economic conditions. ${ }^{13}$

Organisations including the Mental Health Foundation and Faculty of Public Health in the UK have been exploring and prioritising new approaches to tackling this 'failure'. In 2016, they published a joint report, entitled Better Mental Health for All, which makes it clear that mental health problems are as much a public health issue as physical disorders/illness, and that we need to shift the focus away from the current reactive and individual responses to methods of public health prevention, promotion and early intervention. This includes a focus on creating environments in which people can enjoy positive mental well-being, rather than merely avoid mental ill health: the report works with a concept of mental health that runs through a continuum that goes beyond the absence of disease. ${ }^{14}$ It concludes that:

There is strong evidence that investment in the protection and promotion of mental wellbeing, including early intervention and prevention, improves quality of life, life expectancy, educational achievement, productivity and economic outcomes, and reduces violence, antisocial behaviour and crime . . . Strong evidence of the poor outcomes related to having a mental health problem means that prevention and early intervention need to be a priority. Equally, there is evidence that investing in the protection and promotion of mental wellbeing should be emphasised within public mental health. ${ }^{15}$

The report advocates for new ways of thinking in order to 'realise the full potential of public mental health'16 and reduce the burden of mental ill health.

In this paper, we contribute to this narrative strategy and practical agenda by explaining how legal scholarship can provide new and meaningful ways of thinking about and contributing to public mental health. ${ }^{17}$ Just as we share the view that practice in this area should not be characterised as simply reactive to problems once they have arisen, so we envisage a concept of public mental health law that proactively seeks to provide conditions for and protections of positive mental well-being, in addition to governance structures for reactive measures in instances where mental ill health does arise. We start, in the following section, by exploring the development of public health law and mental health law, and their relationship with the broader field of health law. This allows a critical understanding of the advances that we argue are required in scholarship. We then move to consider what legal foundations and approaches may promote and constrain public mental health, and what forms of law and regulation are engaged in public mental health law. We exemplify our discussion with reference to dementia, but consider our arguments here to have broad application and importance for priorities in health law as a field of

11 At 16. See <www.who.int/mental_health/evidence/atlas/mental_health_atlas_2017/en>.

12 Arthur Kleinman, 'Global Mental Health: A Failure of Humanity' (2009) The Lancet 374:9690, 603-04.

13 Brendan D Kelly, Mental Illness, Human Rights and the Law (Royal College of Psychiatrists 2016) 215.

14 Better Mental Health for All: A Public Health Approach to Mental Health Improvement (Mental Health Foundation/Faculty of Public Health 2016) 13. See <www.mentalhealth.org.uk/publications/better-mentalhealth-all-public-health-approach-mental-health-improvement $>$.

15 Ibid 14.

16 Ibid 11.

17 See also the recent special issue of Public Health Ethics (2018) 11(2) compiled by Diego Silva, Cynthia Forlini and Carla Meurk, which explores public mental health ethics. 
study and practice. Our conclusion aims to provide a clearly delineated concept of public mental health law and the rationale for its importance.

\section{Health law as medical law; mental and public health law as outliers?}

\subsection{AN EARLY FOCUS ON MEDICINE AND LAW}

The current wave of scholarship on the relationships between health and law began with the practice of medicine as its primary concern. ${ }^{18}$ In a UK context, this is reflected by the focus of the earliest textbooks, ${ }^{19}$ such as J K Mason and Alexander McCall Smith's Law and Medical Ethics, ${ }^{20}$ Margaret Brazier's Medicine, Patients, and the Law, ${ }^{21}$ and Ian Kennedy and Andrew Grubb's Medical Law: Text and Materials. ${ }^{22}$ Critical historical reflections track the evolution of contemporary 'medical law' as a phenomenon that emerged within or alongside the broader field of bioethics, which also took the doctorpatient relationship as its main point of focus since its emergence in the 1970s. ${ }^{23}$ This narrowing of the field is remarkable in part because, in principle, bioethics has a much wider reach than clinical medicine (and thus an interest that expands beyond situations involving the remediation of ill health within a medical or healthcare setting). The International Association of Bioethics, for example, defines its area of inquiry in the following terms:

Bioethics is the study of the ethical, social, legal, philosophical and other related issues arising in health care and in the biological sciences. ${ }^{24}$

This great breadth, which incorporates, for instance, environmental ethics, the ethics of biotechnological innovation and animal ethics, was not reached through the overwhelmingly dominant debates and discourses of early bioethics. Although scholars, of course, examined those and other wider areas, health law, like bioethics more generally, primarily presented itself as distinctly medical in tone. The influence and allure of anti-medicalisation critiques, such as Ivan Illich's Medical Nemesis, ${ }^{25}$ and the apparent conflation of biomedical ethics and bioethics writ large, meant that the central point of analysis was a universe in which one person - a patient - interacted with one other person - a doctor - with critical inquiry attending to the boundaries of the former's (moral) right to determine what treatments she should receive to serve her interests as she perceived these.

That inquiry could have lain in other areas even within the reach of medicine was not missed as UK medical law developed. Consider the following extract from Joseph Jacob's review of Kennedy and Grubb's Medical Law: Text and Materials, published in 1990:

18 For critique and rich historical context, see further Margaret Brazier and Jonathan Montgomery, 'Whence and Whither "Modern Medical Law"?', published in this special issue.

19 But note that 'medical law' is still the chosen focus of some texts whose first editions came rather later, such as: Emily Jackson, Medical Law: Text, Cases, and Materials (4th edn, Oxford University Press 2016; 1st edn 2006); Jonathan Herring, Medical Law and Ethics (3rd edn, Oxford University Press 2010; 1st edn 2006); Jo Samanta and Ash Samanta, Medical Law (2nd edn, Palgrave 2015; 1st edn 2011).

20 J Kenyon Mason and R Alexander McCall Smith, Law and Medical Ethics (Oxford University Press 1983).

21 Margaret Brazier, Medicine, Patients, and the Law (Penguin 1987).

22 Ian Kennedy and Andrew Grubb, Medical Law: Text and Materials (Butterworths 1989). Although not a textbook, see also Ian Kennedy, The Unmasking of Medicine (Allen \& Unwin 1981).

23 See further Ruth Chadwick and Duncan Wilson, 'The Emergence and Development of Bioethics in the UK' (2018) 26(2) Medical Law Review 183-201; Duncan Wilson, The Making of British Bioethics (Manchester University Press 2014); Kenneth Veitch, The Jurisdiction of Medical Law (Ashgate 2007).

24 See <www.bioethics-international.org/work-progress $>$.

25 Ivan Illich, Limits to Medicine - Medical Nemesis: The Expropriation of Health (Marion Boyars 1976). Note e.g. its impact on Ian Kennedy's thinking: Ian Kennedy, 'What is a Medical Decision?' in Ian Kennedy, Treat Me Right: Essays in Medical Law and Ethics (Clarendon 1988). 
[T] he particular commitments of the compilers are more implicit than expressed; but then it is one of the teacher's tasks to draw these out. Kennedy and Grubb have not excluded much that law teachers may be expected to ask their students to read ... If there is a major omission, it is the scant regard for what, with some understatement, can be called the paternalism of public health law - see their brief discussion of notifiable diseases (pp. 110ff) and compulsory treatment under the Mental Health Acts (pp. 112ff) - which is part of the legacy of Chadwick and contrasts with the common law tradition. For this disregard, however, Kennedy and Grubb must be forgiven because neither public health law nor the regimes which replaced the Victorian Poor laws are their real concern. ${ }^{26}$

The thrust of this observation is important in itself to our current project (see sections 2.2 and 2.3 below), but also reflects a separate defining feature of health law: scholarship here has an ongoing 'self awareness'; it produces internal critiques of the boundary and coherence problems for the field. ${ }^{27}$ Jonathan Montgomery's paradigm-shifting recharacterisation from medical law to healthcare law, notably as expounded in his textbook of that title published in its first edition in 1997 , is a prominent example. ${ }^{28}$ Montgomery explicitly provides practical rationales for the incorporation of broader theoretical commitments and practical points of concern than would be given by health law conceived simply as medical law: a need to look to healthcare systems, the role of institutions, the place of practitioners other than doctors, and the impact of health promotion measures outside of clinical medicine. ${ }^{29}$

Over time, not least because of the influence of scholars such as Montgomery, the field has broadened to capture wider concerns still: bioethics and health law scholarship now boasts extraordinary reach in terms of critical and (inter)disciplinary approaches, applied to myriad areas of practical concern, such as animal law, artificial intelligence, human enhancement, global and planetary health, and so on. We revisit some of these points as the paper progresses, as we argue for the value and importance of public mental health law as a part of and a contributor to the overall field of health law. But at this stage we aim to consider how the sharpening of the early paradigms of (modern) medical law constrained and led to (mis)characterisations of mental and public health: we will show in section 2.2 how mental health and public health came to be presented as 'outliers' in health law and bioethics. The early practical points of focus in medical law, as described above, provide the start of a rationale for this. To explain it fully, we need to consider next how the early framings of medical law create a distorting focal point with 'the autonomous patient', and then explain the impact of this in the galvanisation of received wisdoms and their implications for health law scholarship in the areas of mental and public health.

26 The review is also of Dieter Giesen's, International Medical Malpractice Law: see (1990) 53 Modern Law Review 280-2, 280. It is worth noting that Jacob is himself author of Doctors and Rules: A Sociology of Professional Values (Routledge 1988) (with an extended 2nd edn published in 1999).

27 Cf e.g. Veitch (n 23); Theodore Ruger, 'Health Law's Coherence Anxiety' (2008) 96 Georgetown Law Journal 625; John Coggon, What Makes Health Public? A Critical Evaluation of Moral, Legal, and Political Claims in Public Health (Cambridge University Press 2012) ch 5; Anne-Maree Farrell, John Devereux, Isabel Karpin and Penelope Weller, Health Law: Frameworks and Context (Cambridge University Press 2017).

28 Jonathan Montgomery, Health Care Law (Oxford University Press 1997; 2nd edn 2002).

29 Ibid ch 1. 


\section{2 'EMPOWERMENT' AND THE DISTORTING EFFECT OF THE 'PARADIGM PATIENT'}

The creation of medical law as characterised above was effectively the creation of a particular critical lens. This lens allowed a sharpened focus on a certain genus of questions such as: why and to what extent a patient should be informed before her consent to an intervention is considered meaningful; what reasons and considerations are relevant to a patient's decision to make fatal refusals of treatment; in what circumstances might medical care be said to incorporate rights, for example, to receive euthanasia? This sharpened focus was achieved by developing paradigms that became received analytical assumptions embodied in the idea of the 'autonomous patient'. This patient was an individual whose rights emanated from her being able and rightfully placed, once well informed (again by right), to determine her own interests. Decision-making in a medical context contained both questions of clinical judgement, for which medical expertise was relevant, and questions of wider judgement and values (personal, familial, social, ethical, religious) that were not considered the preserve of the doctor. ${ }^{30}$ And overarching this was a broad scepticism - cynicism even - regarding 'medicalisation', wherein a dominant profession had claimed 'jurisdiction' over questions that ought, it was understood, to be determined by individuals in the vindication of their own rights. ${ }^{31}$

As a matter of logic, analytical points of focus such as 'the autonomous patient' clarify by simplifying: theories bring explanatory and critical potential at the cost of detail and nuance. ${ }^{32}$ Of necessity, the further a theory's paradigms are from reality, the more distorting becomes the lens. Insofar as the starting points of critique allow settled and justified conclusions on questions such as (say) voluntary, active euthanasia for adults who are suffering unbearably and reaching an uncoerced decision, this is fine. But where (say) the paradigm patient is not reflective of the person under discussion (e.g. because she is not able to reach a decision on her best interests), or reflective of the practical context (e.g. because a preventive measure would need to be instituted at a population level and gaining individual consent is not even a theoretical possibility), we come into problems if our analysis is made by reference to 'the autonomous patient'. 33

The simple response to such problems is to recognise the limits of the existing theoretical apparatus and develop appropriate machinery for critique that works with alternative, relevant and defensible paradigms. ${ }^{34}$ However, within the early days of medical law, it might be observed that for practical scenarios that fitted uncomfortably within the dominant paradigms, the problems seemed to be for the cases rather than for the theory, at least by default. ${ }^{35}$ In the current paper, it is pertinent to exemplify this by reference to mental health and public health, although other 'outlier' areas could equally be cited. As noted in Jacob's review, quoted above, mental and public health were acknowledged only largely to be sidelined. They became outliers as a matter, essentially,

30 Cf Kennedy (n 25).

31 See Illich (n 25).

32 Stephen R Latham, 'On Some Difficulties for any Theory of Global Health Justice,' in John Coggon and Swati Gola (eds), Global Health and International Community: Ethical, Political and Regulatory Challenges (Bloomsbury 2013).

33 John Coggon, 'Would Responsible Medical Lawyers Lose their Patients?' (2012) 20(1) Medical Law Review 130-49; John Coggon, 'Mental Capacity Law, Autonomy, and Best Interests: An Argument for Conceptual and Practical Clarity in the Court of Protection' (2016) 24(3) Medical Law Review 396-414.

34 See Bruce Jennings, 'Frameworks for Ethics in Public Health' (2003) 9(2) Acta Bioethica 165-76; Nuffield Council on Bioethics, Public Health - Ethical Issues (Nuffield 2007) 'Introduction'.

35 Consider the critique provided in Angus Dawson, 'The Future of Bioethics: Three Dogmas and a Cup of Hemlock' (2010) 24(5) Bioethics 218-25. 
of convention, even whilst they could have been incorporated more fully within health law as 'medical law'. And this is of great significance because, by virtue of their exclusion, they were essentially placed in a position where defences of practice had to be made against uncritical acceptance of assumptions born of the paradigms of mainstream medical law. For mental health this is well represented by critiques framed as 'medicalism' versus 'legalism'. ${ }^{36}$ For public health the same is true by references to 'healthism' or 'nanny statism' versus individual right. ${ }^{37}$ And both mental and public health are united not just by reference to their relative neglect in mainstream medical law: they also share a number of a salient overlapping analytical concerns. In particular, both give rise to questions of the common good and the potential tensions between individual and public interests (e.g. in relation to measures generated in instances where an individual is considered to be a threat to the community); both draw in considerations of paternalism and intervention without consent (thus challenging the assumed wisdom of 'the autonomous patient' and her being positioned best to recognise her interests); and, as explored in section 3.2 of this paper, they invite similar forms of framing when we consider how they ought to be addressed.

The adversarial framing of competing principles or theoretical commitments that we characterise here may at first seem simplistic, but it is emblematic of the application of theory in practical questions concerning bioethics and health law. ${ }^{38}$ Medical law had the patient's right to non-interference secured as an almost unchallengeable ethical - and, if sometimes only in principle, legal - right. ${ }^{39}$ The duty to respect a patient's entitlement to be treated only following free and informed consent became the cardinal principle (albeit that on the latter, the law somewhat lagged behind the ethics).$^{40}$ In contrast, the concerns of mental health and public health were more challenging: respect for individual rights was placed at no less of a premium, but in a context where the rationales and justifications concerning the acceptability for treatments or interventions without consent were not the same. Even allowing that we might end up at the same conclusion - i.e. that intervention cannot be justified and protections of bodily integrity should be absolute distinct theorising needed to be achieved. We move from a universe with just two people in it, and with our ethical source of concern just being one person (the autonomous patient), to a more complex social context, in which rejections of paternalism are not so straightforward (can we really accept that we are justified deferring to the individual's perspective of what serves her interests?) and in which questions of the common good and impacts on others cannot be ignored (are the person's individual interests exhaustive of our ethical concern?).

36 As first described by Kathleen Jones, see Asylums and After: A Revised History of the Mental Health Services from the Early 18th Century to 1990 (Athlone Press 1993).

37 Petr Skrabanek, The Death of Humane Medicine and the Rise of Coercive Healthism (Social Affairs Unit 1994); John Coggon, The Nanny State Debate: A Place Where Words Don't Do Justice (Faculty of Public Health 2018).

38 Cf Michael Dunn and Charles Foster, 'Autonomy and Welfare as Amici Curiae' (2010) 18(1) Medical Law Review 86-95.

39 Margaret Brazier, 'Do No Harm - Do Patients Have Responsibilities Too?' (2006) 65(2) Cambridge Law Journal 397-422; John Coggon, 'Varied and Principled Understandings of Autonomy in English Law: Justifiable Inconsistency or Blinkered Moralism?' (2007) 15(3) Health Care Analysis 235-55.

40 Sidaway v Board of Governors of the Bethlem Royal Hospital and the Maudsley Hospital [1985] AC 871; Chester v Afshar [2004] UKHL 41; Montgomery v Lanarkshire Health Board [2015] UKSC 11; General Medical Council, Consent: Patients and Doctors Making Decisions Together (General Medical Council 2008); Anne Maree Farrell and Margaret Brazier, 'Not So New Directions in the Law of Consent? Examining Montgomery v Lanarkshire Health Board' (2016) 42(2) Journal of Medical Ethics 85-8; Rob Heywood and José Miola, 'The Changing Face of Preoperative Medical Disclosure: Placing the Patient at the Heart of the Matter' [2017] 133 Law Quarterly Review $296-321$. 
The presumption towards gradations in the role of different principles (autonomy, welfare, the common good etc.) that are prima facie required by mental and public health presents a contrast with the zero-sum absolutism of (say) autonomy versus paternalism in mainstream medical law. Even in the context of the paradigm patient, medical law has started to develop towards a less absolutist framing, accounting for empirical discourses on the realities of decision-making and critical accounts such as 'relational autonomy'. But, in the early days of modern medical law, the contrast was with the robust persona of the autonomous patient. The ill-suitedness of the paradigm patient in the context of mental health was clearly recognised, and noted, for example, by Phil Fennell, who wrote in 1990:

There is now widespread acknowledgement of the folly of rigid insistence upon the ascendancy of patient autonomy over paternalism where the result would be harm to the patient. Paternalism is recognized as legitimate up to a certain point. 41

Similarly, in their leading textbook on Public Health Law, Lawrence Gostin and Lindsay Wiley reflect back on the dominant concerns of public health, indicating the contrast with mainstream medical law:

Public health has historically constrained the rights of individuals and businesses to protect community interests. Whether through the use of reporting requirements affecting privacy, mandatory testing or screening affecting autonomy, environmental standards affecting private property, industrial regulation affecting economic freedom, or isolation and quarantine affecting liberty, public health has not shied away from controlling individuals and businesses for the aggregate good. ${ }^{42}$

It is clear that these wider contexts and concerns impact the basis of, and thus conclusions to, analysis. And we also see how the framing, when dominated by a medical law paradigm of self-reliant individuals with indefeasible rights, is problematic from the start. ${ }^{43}$ Early medical law could triumph the autonomous patient and, consistently with this, reduce the medical practitioner to a party whose role was limited to the competence afforded by a technical expertise that could not speak to final value judgements or what should ultimately be done to a patient for her own good without her express agreement. And the 'universe' in which this happened was largely confined to a clinical situation with no wider societal considerations at play. However, in mental health and public health, even at the level of theory, it could not without questionable assumptions be argued that such a position would hold. ${ }^{44}$ In both areas, inevitably, value judgements external to those of the patient (or, given the broader contexts, person or citizen) would be brought to bear on decisions that directly impacted the individual and her choices. On settled analysis, of course, we might argue that this is wrong: as libertarian scholars such as Szasz and Skrabanek did respectively in relation to mental and public health. ${ }^{45}$ But in the alternative, where concerns for well-being and welfare at individual and population levels arose, an

41 Phil Fennell, 'Inscribing Paternalism in the Law: Consent to Treatment and Mental Disorder' (1990) 17(1) Journal of Law and Society 26-51, 26.

42 Lawrence O Gostin and Lindsay Wiley, Public Health Law: Power, Duty, Restraint (3rd edn, University of California Press 2016) 11.

43 Cf Jennings (n 34).

44 Lawrence O Gostin, 'Public Health: The "Population" as Patient' in Catherine D DeAngelis (ed), Patient Care and Professionalism (Oxford University Press 2014).

45 Thomas Szasz, Law, Liberty, and Psychiatry: An Inquiry into the Social Uses of Mental Health Practices (Syracuse University Press 1989 [1963]); Skrabanek (n 37). 
alternative framing was needed. However, we see that the sort of gradations indicated, for example, in Fennell's words directly above, contended with the settled wisdoms of medical law.

\subsection{PARAllelS AND PARADIGMS IN THE OUTLIER AREAS OF MENTAL AND PUBLIC HEALTH LAW}

The previous discussion has indicated that mental health and public health existed as outliers in two particular ways in health law. First, as a practical matter they suffered relative neglect in medico-legal scholarship. Of course, it is true that significant figures, such as Brenda Hale (Hogget), Phil Fennell, Lawrence Gostin and Robyn Martin, were considering these fields as a whole, and specific questions within them, for example: treatment without consent for psychiatric conditions; notifiable diseases. But measured by weight of scholarship, there was far less attention to these than was received by questions in clinical medicine, such as informed consent, euthanasia and so on. Second, and probably as a consequence, mental health and public health suffered neglect because settled conclusions on 'the autonomous patient' meant that the dice were loaded against analyses that could suitably accommodate concerns for autonomy and for welfare and the common good. ${ }^{46}$

In short, the upshot of early modern medical law was a framing that contraposed medical paternalism/interference on the one hand with individual rights on the other. In regard to mental health and public health this was significant and to a good extent valuable. An unbridled medicalism in mental health was demonstrably problematic, and greater legal protections for psychiatric patients overdue. ${ }^{47}$ Equally, public health measures - notably responses to HIV/AIDS - clearly invited responses that recognised, respected and protected individual rights. ${ }^{48}$ This was all the more important as the individuals under discussion were often members of vulnerable and/or otherwise disadvantaged or marginalised groups. Nevertheless, it allowed the enforcement of a perception that mental and public health were challenges to, and to be challenged by, human rights: the two fought against one another. And the apparent (moral) soundness of such a framing was underscored by the concern in bioethics and medical law to frame patients as autonomous rights-holders whose decision-making should not be interfered with, for their own good, by medical professionals or the state. A preponderance of citations of John Stuart Mill's 'harm principle' (generally with little regard for a wider discussion of On Liberty) came to serve as a knock-down argument:

$[\mathrm{T}]$ he only purpose for which power can be rightfully exercised over any member of a civilized community, against his will, is to prevent harm to others. His own good, either physical or moral, is not a sufficient warrant. He cannot rightfully be compelled to do or forbear because it will be better for him to do so, because it will make him happier, because, in the opinion of others, to do so would be wise, or even right ... The only part of the conduct of any one, for which he is amenable to society, is that which concerns others. In the part which merely concerns himself, his independence is, of right, absolute. Over himself, over his own body and mind, the individual is sovereign. ${ }^{49}$

46 Cf Coggon (n 33).

47 Lawrence O Gostin, A Human Condition Volume I: The Mental Health Act from 1959 to 1975: Observations, Analysis and Proposals for Reform (MIND 1975).

48 Richard D Mohr, Gays/Justice: A Study of Ethics, Society, and Law (Columbia University Press 1988).

49 John Stuart Mill, On Liberty, Edward Alexander (ed) (Broadview 1999 [1859]) 52. 
The impact of this type of analysis is compounded by its apparent basis in civil and political rights: rights to be left alone, with little (perhaps no) concern being given to economic, cultural and social rights. So again, the concerns that might underpin mental and public health interventions, are sidelined. In the next section, we explore and promote challenges to the paradigms that we have presented here and consider their application in practice. Our argument rests on what we consider to be a better picture, in which mental and public health are framed as part of human rights, rather than oppositional to them. We aim to show how a coming together of a reconceived field of public mental health law can lead to a richer and more productive health law overall, not least in affording greater potential for achieving parity of esteem between mental and physical health.

\section{Beyond restraint: human rights as a framework for action in public mental health}

\subsection{EMERGING FROM THE SHADOWS: MENTAL HEALTH AND PARITY OF ESTEEM}

Various narrative, advocacy and analytical advances at the global level concerning mental health and human rights help to demonstrate how mental health is emerging from the shadows as a public health concern, and how human rights can play a key role in promoting preventive and population-level health improvement approaches to mental health. The WHO has helped to 'sharpen the focus' on mental health in the last decade by launching the Mental Health Gap Action Programme (mhGAP), ${ }^{50}$ which aims to scale up services for mental disorders, especially for low- and middle-income countries. The Grand Challenges in Global Mental Health, ${ }^{51}$ launched in 2010, supports new research to focus collective efforts on global mental health. These initiatives have been followed by commitments from member states to combat mental ill health in the WHO Mental Health Action Plan 2013-2020.52

At a domestic level, focusing here on England, there are also factors contributing to the shift away from a reactive approach, towards preventive approaches to mental health and well-being. A recent review of mental health legislation has identified mental health as emerging 'into the light' 53 with an explicit commitment to achieving 'parity of esteem' and equal treatment for mental and physical ill health. To be realised, of course, such a commitment requires adequate bolstering at political (including economic), legal, social and personal levels. And the first two of these are, we suggest, prerequisites to the sustainable achievement of the final two.

At least on its face, it can be shown that the political climate has shifted to recognise the need for a population approach to tackle the risk factors and determinants of mental ill health and to promote good mental health. Prime Minister Theresa May announced in 2017:

[A] step-change in the way that we deal with these issues. I want to see mental health addressed not just in our hospitals, but in our classrooms and communities. I want to see the stigma stripped away so that no-one in this country feels unable to talk about what they're going through or seek help. I want

50 See <www.who.int/mental_health/mhgap/en>.

51 See further Pamela Y Collins et al, 'Grand Challenges in Global Mental Health' (2011) 475:7534 Nature 2730 .

52 See <www.who.int/mental_health/publications/action_plan/en>.

53 See The Independent Review of the Mental Health Act: Interim Report (1 May 2018) 5 <https://assets.publishing.service.gov.uk/government/uploads/system/uploads/attachment_data/file/7039 19/The_independent_Mental_Health_Act_review_interim_report_01_05_2018.pdf>. 
to see a focus on prevention as well as treatment, especially since so many adult mental health problems - which 1 in 4 of us will suffer from at any one time begin in childhood. ${ }^{54}$

This political commitment is, to an extent, supported by legislation and government policy. The Health and Social Care Act 2012 introduced the first explicit duty on the Secretary of State to promote physical and mental health and prevent, diagnose and treat physical and mental ill health. ${ }^{55}$ This legal duty is reinforced by local authorities' health improvement duties, as well as the Care Act 2014, which imposes a further duty on local authorities to promote individual well-being, defined as including emotional, physical and mental health. ${ }^{56}$ And it is underscored politically by the NHS Constitution, which explains that the NHS is designed to diagnose, treat and improve physical and mental health'. ${ }^{57}$ Additionally, the NHS England strategy published in 2016, Five Year Forward View for Mental Health, 58 is committed to working towards a more equal response across mental and physical health, and achieving parity between the two.

However, we might question the real strength and impact of these political and legislative moves and commitments. An official report in 2017 has highlighted that, whilst there has been some encouraging early progress, there 'remains a long distance to travel to achieve true parity'. ${ }^{59}$ It outlines the key foci for future development: to continue to invest in the mental health workforce and services, as well as preventive mental health approaches; and to promote a 'fresh mindset' to tackle inequalities, stigma and discrimination. Moreover, the recent report of the independent review of the Mental Health Act (MHA) 1983 has been equally critical of the lack of appropriate and preventive mental health services and support, although regrettably, the review fell considerably short of recommending a positive entitlement to support/treatment services and a complete overhaul of current mental health legislation. ${ }^{60}$

The need for greater work at political and legal levels is underscored if we look at evidence at the social and personal levels. This suggests that attitudinal shifts are necessary if mental health is to be understood in parity with physical health, albeit that things appear to be moving in the right direction, as the recent independent review of the MHA report ${ }^{61}$ and Attitudes to Mental Illness 2014 Research Report ${ }^{62}$ prepared for Time to

54 'Mental Health Problems Are Everyone's Problem: Article by Theresa May' (9 January 2017) <www.gov.uk/government/speeches/mental-health-problems-are-everyones-problem-article-by-theresamay>.

55 Health and Social Care Act 2012, s 1(1).

56 Ibid s 12; Care Act 2014, ss 1(1) and 1(2).

57 See <www.gov.uk/government/publications/the-nhs-constitution-for-england $>$.

58 (February 2016) located at <www.england.nhs.uk/mental-health/taskforce>. See also The NHS Long Term Plan (14 February 2019), which has reaffirmed the government's commitment to achieving parity of esteem for mental health, located at <www.england.nhs.uk/long-term-plan $>$.

59 See <www.england.nhs.uk/wp-content/uploads/2017/03/fyfv-mh-one-year-on.pdf >

60 Modernising the Mental Health Act: Increasing Choice, Reducing Compulsion: Final Report of the Independent Review of the Mental Health Act 1983 (December 2018) 7 <www.gov.uk/government/groups/independent-review-of-themental-health-act>.

61 Ibid.

62 (April 2015) See <www.time-to-change.org.uk/sites/default/files/Attitudes_to_mental_illnes s_2014_report_final_0.pdf>; see also Public Health England/National Centre for Social Research, Attitudes to Mental Health Problems and Mental Wellbeing: Findings from the 2015 British Social Attitudes Survey $<$ www.bsa.natcen.ac.uk/media/39109/phe-bsa-2015-attitudes-to-mental-health.pdf>. 
Change ${ }^{63}$ demonstrate. There are some positive indications of greater levels of public understanding in England between 2008 and 2014, evidenced by the reported 9 per cent increase in willingness to live with someone who has a mental health problem (from $57 \%$ to $66 \%$ ); and a 7 per cent increase in willingness to work with someone who has a mental health problem $(69 \%$ to $76 \%$ ). Moreover, 78 per cent of respondents believed that for too long people with mental illness have been the subject of ridicule, and 95 per cent believed that people with mental illness are subject to stigma and discrimination. Nevertheless, it is still worrying that over a third of survey respondents thought that people with a mental health problem are prone to violence, and only 40 per cent would be comfortable speaking to their employer about a mental health problem.

The Better Mental Health for All report, discussed in the introduction to this paper, provides further impetus to champion a fresh, more holistic approach (including preventive and health improvement measures) and highlights the need for legal and political support for this. The report recognises that current models are highly responsive, while effective prevention of illness and promotion of well-being require a different strategy:

Interventions which focus on the positive have added value over those which focus on finding or preventing the negative. Promoting mental wellbeing moves the focus away from illness and is central to an individual's resilience, social purpose, autonomy and ability to make life choices. ${ }^{64}$

When considering the role of law here, both for its practical force and its expressive nature in regard to social values and priorities, it is worth emphasising that regulatory (especially legal) frameworks for mental healthcare and treatment in England are coercive, reactive, and very much focused on crisis intervention. For example, the admission and treatment provisions of the MHA justify the use of compulsory care, triggered when mental health has deteriorated to a point where it is of sufficient nature and severity to justify in-patient treatment. We do not for a moment wish to deny the importance of law in contexts of acute psychiatric illness, or the need for reform in this area in ways that allow real and meaningful involvement and participation of the persons who would be affected by such laws, as required by Article 4(3) of the UN Convention on the Rights of Persons with Disabilities (CRPD). But the near-exclusive emphasis lent by this overwhelmingly reactive approach allows the sidelining of some of the key risk factors for mental ill health, which occur throughout the life-course and across communities and which also would benefit from the normative and practical support of legal, rather than just (potentially quite empty) political, commitments. ${ }^{65}$ Indeed, a report in 2018 by the Care Quality Commission in England into rising detentions under the MHA suggests that the ongoing rise in compulsory detentions (the number of detentions increased by $40 \%$ - from 45,484 to 63,622 - between 2005/2006 and 2015/2016) may be symptomatic of a system under 'considerable pressure'. The report attributes this to a number of factors, including declining access to community services and an increase in the prevalence of risk factors for detention, such as rising inequality, social exclusion and drug/alcohol

63 Time to Change is a growing social movement in the UK campaigning to improve attitudes and behaviour towards people with mental health problems, with the aim of eliminating mental health discrimination and stigma - see further <www.time-to-change.org.uk>.

64 Better Mental Health for All (n 14) 28.

65 Cf also the distinction in conceptualisation of, and responses to, 'crisis resolution' as contrasted with 'general support' in Piers Gooding, Bernadette McSherry, Cath Roper and Flick Grey, Alternatives to Coercion in Mental Health Settings: A Literature Review (Melbourne Social Equity Institute, University of Melbourne 2018). 
misuse. ${ }^{66}$ The status quo only sharpens the narrow lens to much analysis, and thus scholarly priorities, in health law described in section 2 of this paper.

Let us therefore explore the wider landscape, and explain the broader space for law within it. Dahlgren and Whitehead argued several decades ago that susceptibility to mental health problems is determined by a combination of individual risk factors, influenced by settings, and broader socio-economic, cultural and political factors. ${ }^{67}$ There is also an important family dimension, as relationships moulded in formative years contribute to health and well-being in later life. This point is emphasised too in Better Mental Health for All:

[T] he social, physical and economic environments in which people are born, grow, live, work and age have important implications for mental health. ${ }^{68}$

Acceptance of these evidence-based concerns represents a shift away from the biomedical model, which has, until recently, dominated beliefs about physical and mental health and, as outlined above, the shape and scope of bioethics and health law. The biomedical model emphasises the genetic and biological causes of disease, with a consequent focus on pharmacological and clinical solutions: it is narrow and (generally) responsive. And, accordingly, it ignores the impact of the social and environmental determinants of health, with a consequent failure to account for measures that are broader and pre-emptive. Traditionally, psychiatry has focused on treatment and 'tertiary prevention': i.e. slowing the progress of disease/disability. ${ }^{69}$ If health law is to serve mental as well as physical health, we need to move to framings that accord with growing scientific awareness of the role of mental health improvement and early detection, and acceptance of the need to develop interventions that might reduce the incidence of mental disorders. ${ }^{70}$

To do this, we cannot just rely on (healthcare) professionals' understanding or capacity to intervene. Health law and policy are crucial precisely because many of the general risk factors for mental ill health, such as social exclusion and inequality, cannot be addressed by psychiatrists or clinicians. The same is true for the provision and maintenance of environments that promote positive well-being. A vast range of other specialists and institutions need to cooperate within a framework that allows shared means and agendas. This includes colleagues in primary health and social care, education, employment, housing and community sectors. As Better Mental Health for All recognises:

A truly multidisciplinary and inter-sectoral approach must be adopted as no one discipline has all the knowledge or power to effect the required level of change. ${ }^{71}$

It is also imperative to put the voices of those with lived experience of mental ill health at the heart of legislative and policy responses, in line with the ethos of the CRPD.

66 Care Quality Commission, Mental Health Act: The Rise in the Use of the MHA to Detain People in England (Care Quality Commission 2018) 4, 23.

67 Göran Dahlgren and Margaret Whitehead, Policies and Strategies to Promote Social Equity in Health (Institute for Future Studies 1991).

68 Ibid 9.

69 Celso Arango et al, 'Preventive Strategies for Mental Health' (2018) 5(7) The Lancet Psychiatry 591-604.

70 Ibid.

71 Better Mental Health for All (14) 28. 
Service users are demanding a stronger commitment to early intervention and preventive approaches, as well as greater respect for and promotion of the right to (mental) health. ${ }^{72}$

Within this new agenda there is a significant part for law to play, and thus a pivotal role for health law scholarship. Law's fundamental value as a source both of empowering authority and institutional restraint makes it an essential, if understated, part of the solution. As indicated in this section, this comes both through law's regulatory/coordination capacity and its expressivist functions. We approach this analysis from a perspective of wishing to see legal methods of empowerment being developed alongside more widely discussed efforts for legal reform in relation to reactive laws on mental health, disability and incapacity. As such, in the current paper, even whilst we draw from the advocacy and learning of the UN Committee on the Rights of Persons with Disabilities, we do not engage with questions of national legal reforms aimed at achieving equality before the law on the abolition of mental health laws (as these are framed, for example, within the UK). ${ }^{73}$ This is not because of a perceived unimportance to these topics, but because we are aiming to generate a wider research agenda too. A key point of the neglect of the sorts of interventions and measures that we are arguing for is that their less 'profound' nature leads to their being missed; and thus also the great good that may be done. We would forcefully advocate (and are doing so in other areas of our work) for the legal rights of persons who suffer discrimination in the enjoyment of their legal capacity. Here, however, we aim to explore the place of law in providing conditions for good mental health and well-being; looking beyond reactive methods of intervention and the place of law in relation to this. To do this, we will now argue that recent developments in international human rights law provide a particularly useful framework to represent and advance the need and approach that we have identified and operationalise the field of public mental health law.

\subsection{Public health, Mental heAlth AND human Rights: CONFLICT OR CONFLUX?}

Better Mental Health for All, as we have shown, reinforces a new mindset and the need to reconceptualise the relationships between health, mental health and public health. As the report makes clear, the time has come for us to 'act in an empowering way to combat inequalities and the powerlessness that can accompany them'. ${ }^{74}$ We have explained how and why health law, broadly enough conceived, is an essential tool to work towards achieving those goals: law shapes and underpins the necessary socio-political infrastructures and provides mechanisms for assuring that necessary and proportionate health responsibilities are realised. In this section, we consider how a human rights framing specifically can motivate both practical and normative support for law as it impacts public mental health practice, policy and obligations. It is axiomatic that an environment that respects and protects basic civil, political, socio-economic and cultural rights is fundamental to mental health. Put conversely, neglect of such rights is neglect of duties concerning mental health and well-being. This logically suggests that a powerful alliance is found between human rights advocacy and mental health promotion, with compelling implications for the obligations of governmental and other socio-political actors.

72 See, for example, National Survivor User Network, 'Our Voice our Vision our Values’ (Members’ Manifesto 2017), see <www.nsun.org.uk/our-manifesto>; Hearing Voices Network, The Mental Health Act: An Alternative Review (Hearing Voices Network December 2018) <www.hearing-voices.org/news/alternative-mental-healthact-review $>$.

73 See Committee on the Rights of Persons with Disabilities, General Comment No 1 (2014) (CRPD/C/GC/1 2014), especially paras 50-2.

74 Above (n 14) 11. 
Many scholars, from across fields, have identified that human rights are universal norms which are powerful tools in advancing the rights of vulnerable persons and groups. Gostin et al argue that, unlike some ethical principles or standards, human rights 'are internationally recognized and globally accepted . . . and governments have agreed to be legally bound to upholding [them]'. ${ }^{75}$ Moreover, by defining rights-holders, duty-holders and the nature of obligations, human rights frameworks 'allow a much clearer opportunity to establish accountability (typically of government) for the realization of rights and creates a range of mechanisms to hold governments accountable', as well as 'offering a framework for pro-active development of policies and programs such that health objectives can be operationalized in ways that are consistent with human rights' ${ }^{76}$

Nevertheless, historically there has been scepticism about the relationship between public health and human rights. ${ }^{77}$ By focusing predominantly on individuals and processes, human rights approaches may be viewed as conceptually and theoretically contrary to, or in tension with, the collective or population approaches that are central to public health. ${ }^{78}$ Such a view might seem particularly sustainable within an English context, given that domestically justiciable human rights, enforceable against public authorities under the Human Rights Act 1998, are classically conceived as civil and political ('negative') rights. However, more recent developments in rights instruments, discourse and methodologies have witnessed a more nuanced and 'positive' approach, and a shift towards tackling wider health inequalities. ${ }^{79}$ In the early days of public health ethics, ${ }^{80}$ there were notable examples of human rights being used successfully: in particular, in relation to HIV. ${ }^{81}$ Such examples prompted a move to:

[R]ethink how population approaches to health can respond to public health crises based on inequalities and exclusion, and has led us to devise new ways to integrate human rights into public health. ${ }^{82}$

In accordance with this outlook, Paul Hunt, former UN Special Rapporteur for Health, argues that advancements in rights-based approaches since the turn of the new millennium have moved the focus away from processes and civil/political rights, to a more contextual and less individualised approach. ${ }^{83}$ For some, 'greater attention has been brought to negative health outcomes, and the terrain of human rights increasingly

75 Lawrence O Gostin et al, The Domains of Health Responsiveness - A Human Rights Analysis (WHO Health and Human Rights Working Paper Series No 2 2003) 4.

76 Leslie London, 'What is a Human Rights Based Approach to Health and Does It Matter?' (2008) 10(1) Health and Human Rights 65-80, 68.

77 A notable example, given his more recent advocacy, is found in: Lawrence O Gostin, 'Public Health, Ethics, and Human Rights: A Tribute to the Late Jonathan Mann' (2001) 29 Journal of Law, Medicine and Ethics 12130.

78 Cf Marcel Verweij and Angus Dawson, "The Meaning of "Public" in "Public Health" in Angus Dawson and Marcel Verweij (eds), Ethics, Prevention, and Public Health (Oxford University Press 2007).

79 Kumanan Rasanathan, Johanna Norenhag and Nicole Valentine, 'Realizing Human Rights-based Approaches for Action on the Social Determinants of Health' (2010) 12(2) Health and Human Rights 49-59, 49.

80 Nancy Kass, 'Public Health Ethics: From Foundations and Frameworks to Justice and Global Public Health' (2004) 32(2) Journal of Law, Medicine and Ethics 232-42.

81 Jonathan M Mann, 'Medicine and Public Health, Ethics and Human Rights' (1997) 27(3) Hastings Center Report 6-13.

82 London (n 76) 66.

83 Paul Hunt, 'The Health and Human Rights Movement: Progress and Obstacles' (2008) 15(5) Journal of Law and Medicine 714-24. See also WHO, A Human Rights Approach to Health (WHO 2010). See also Office for the High Commissioner for Human Rights, CESCR General Comment No 14: The Right to the Highest Attainable Standard of Health (Art 12) (Office for the High Commissioner for Human Rights 2000). 
intersects with the social determinants of health'. ${ }^{84}$ This more recent and gradual change in perspective in the context of public health and human rights is to be contrasted with the longer-standing and more highly discernible relationship between mental health and human rights. Gostin and Gable have described the symbiotic relationship between human rights and mental health, characterising them as 'mutually reinforcing', and both 'powerful, modern approaches to advancing human well-being'. ${ }^{55}$ English mental health law has been heavily influenced and shaped by human rights over the last three decades. However, this may be represented as basing itself in the antagonism between individual rights and collective good that we have just suggested historically was seen to set human rights and public health apart. Human rights' historical links to mental health may be seen as obtaining in large part in protection of civil and political rights; individuals' 'negative' freedoms against undue state (or state-sanctioned) interference.

Amongst key examples to support this claim, consider that a successful challenge in the European Court of Human Rights resulted in key changes to procedural safeguards in the then Mental Health Bill, as it passed through Parliament in the early 1980s. ${ }^{86}$ Or note that one of the first declarations of incompatibility under s 4 of the Human Rights Act related to a provision of the MHA. ${ }^{87}$ That things should be framed thus is unsurprising: these legal challenges are rooted in the European Convention on Human Rights (ECHR), where conceptualisations of rights are, as indicated above, focused on individual and process-driven safeguards. ${ }^{88}$ But does this mean that a public mental health approach would be bound to fail? We would argue not. Bartlett et al, in their book Mental Disability and the European Convention on Human Rights, describe how 'mental disability has come of age as a subject of concern under the ECHR', but these rights are 'only the starting point'. 89 There are clear signs, since the introduction of the CRPD, that human rights protection is now moving towards a broader conception of rights and positive entitlements in the context of mental impairment and disability. ${ }^{90}$ As noted in para (y) of the CRPD's preamble:
[A] comprehensive and integral international convention to promote and protect the rights and dignity of persons with disabilities will make a significant contribution to redressing the profound social disadvantage of persons with disabilities and promote their participation in civil, political, economic, social and cultural spheres with equal opportunities, in both developing and developed countries.

84 Rasanathan et al (n 79).

85 Ibid.

86 See $X v U K(1982) 4$ EHRR 188.

$87 J T v U K[2000]$ ECHR 133.

88 See, for example, Genevra Richardson, 'The European Convention and Mental Health Law in England and Wales: Moving beyond Process?’ (2005) 28 International Journal of Law and Psychiatry 127-39; Phil Fennell and Urfan Khaliq, 'Conflicting or Complementary Obligations? The UN Disability Rights Convention, the European Convention on Human Rights and English Law' (2011) 6 European Human Rights Law 662-74.

89 International Studies in Human Rights, vol 90 (Martinus Nijhoff 2007) 28.

90 See, for example, Peter Bartlett, 'The United Nations Convention on the Rights of Persons with Disabilities and Mental Health Law' (2012) 75(5) Modern Law Review 752-78; George Szmukler et al, 'Mental Health Law and the UN Convention on the Rights of Persons with Disabilities' (2014) 37 International Journal of Law and Psychiatry 245-52; Penny Weller, 'The Convention on the Rights of Persons with Disabilities and the Social Model of Health: New Perspectives' (2011) Journal of Mental Health Law 74-83; Jill Stavert, 'Mental Health, Community Care and Human Rights in Europe: Still an Incomplete Picture?' (2007) Journal of Mental Health Law 182-93. 
Overall, the CRPD aims for the eradication of barriers for persons with disabilities to 'full and effective participation in society on an equal basis with others'. ${ }^{91}$ Of necessity, this requires the implementation of 'positive' measures. Article 4(2) of the CRPD provides, furthermore, that: 'With regard to economic, social and cultural rights, each State Party undertakes to take measures to the maximum of its available resources ...' And Article 9, for example, enumerates specific obligations for provision of means to ensure accessibility to 'enable persons with disabilities to live independently and participate fully in all aspects of life'. In line with the wider developments in human rights discourse, the paradigm under the CRPD has shifted away from the medical model in mental health, to a social model founded on all persons as rights-holders.

As we move to such framings, with the consequent inclusion of social, economic and cultural claims, human rights frameworks represent a source of important levers to address health inequalities, promote positive well-being, and create healthier societies. ${ }^{92}$ Our primary jurisdictional focus within this paper is England, but we might note that, in Scotland, human rights approaches framed by reference to the human right to health are gaining strong social and political purchase (including through NHS Health Scotland) in public health advocacy and agendas. ${ }^{93}$ There are real opportunities to learn from the Scottish experience and harness it along with the potential of the CRPD. This would expose the potential for law to bind together ethical, public and mental health approaches and shift the focus to tackling mental ill health and health inequalities in way that is consistent with the position embraced by the current UN Special Rapporteur on Health. ${ }^{94}$ His 2017 report on the right to health reinforces the need for a 'paradigm shift', moving away from biomedical and paternalistic approaches towards a rights-based and holistic approach to the care and governance of mental health:

Population-based approaches to mental health promotion move health systems beyond individualized responses towards action on a range of structural barriers and inequalities (social determinants) that can negatively affect mental health. ${ }^{95}$

The report recognises, however, that population-level approaches do not work in isolation. Another critical strand of a human rights approach is recognising the need for empowerment and effective agency to address the conditions that create vulnerability. 96 It is essential for individuals and their families to be legally empowered and be able to hold governments to account. Thus, what we refer to as a 'holistic' approach is needed; an approach that combines individualist framing of rights with collective/public ones. And to be effective, as emphasised, these require sound and effective developments in law and policy.

91 UNCRPD, Article 1.

92 Paul Hunt and Gunilla Backman, 'Health Systems and the Right to the Highest Attainable Standard of Health' (2008) 10(1) Health and Human Rights 81-92, 81.

93 This is a very broad and ambitious agenda, where the right to health is directly related to social determinants theses, and leads to a focus across the life-course, and across personal, community, occupational and political sectors. By taking a human right to health approach, the advocacy seeks to assure standards in public policy that will effect change by direct reference to concepts of health and well-being. See $<$ www.healthscotland.scot/health-inequalities/the-right-to-health>; see also <www.scottishhumanrights.com>.

94 Report of the Special Rapporteur on the Right of Everyone to the Enjoyment of the Highest Attainable Standard of Physical and Mental Health A/HRC/35/21 (March 2017).

95 Ibid 16.

96 Rasanathan et al (n 79) 68. 


\subsection{THE DEMENTIA 'EPIDEMIC': A CASE STUdY}

Dementia provides a pertinent example to demonstrate the essential place of law and the soundness of a public mental health approach that is framed by reference to human rights. It exposes the need to move beyond responsive interventions and 'negative' individual rights, and beyond the narrow medical law paradigms and conceptual antagonisms and binaries, to recognise the value of proactive and preventive approaches.

Dementia is a leading cause of death in the UK. ${ }^{97}$ The Alzheimer's Society suggests that 850,000 people are currently living with dementia in this country, and that number is projected to increase to 2 million by $2050 .{ }^{98}$ Globally, the number of people living with dementia will increase from 50 million in 2018 to 152 million in 2050 - an increase of 204 per cent. ${ }^{99}$ The WHO estimates that the global number of deaths from dementia will increase by 40 per cent from 2015 to $2030 .{ }^{100}$ These figures suggest that we are on the verge of a global dementia epidemic.

Dementia can be described as:

[A] clinical state where a decline in cognitive function, such as loss of memory, judgment, language, complex motor skills and other intellectual functions, leads to a decline in independent daily function. ${ }^{101}$

It is a recognised psychiatric disorder, included in both the American Psychiatric Association's Diagnostic and Statistical Manual of Mental Disorders IV (DSM-IV-TR), and the WHO International Classification of Disease (ICD-10) criteria. ${ }^{102}$ Dementia results in a progressive decline of multiple areas of function, including memory, reasoning and communication skills. This decline may be accompanied by psychological and behavioural symptoms, such as depression and psychosis. Persons with dementia may, at varying stages throughout the progression of the condition, require treatment that must be authorised under mental health or capacity legislation, due to the nature of dementia and its impact on cognitive function and decision-making ability.

The causes of dementia are multifaceted. Many do stem from genetic factors, but it is increasingly recognised that 'lifestyle' and environment provide major risk factors. ${ }^{103}$ Alzheimer's Research UK data suggest that 40 per cent of people would adopt a healthier lifestyle to reduce their risk of dementia. ${ }^{104}$ Several studies have suggested a link between mentally-stimulating leisure activities and a reduced risk of dementia. ${ }^{105}$ Indeed, National Institute for Health and Care Excellence (NICE) guidance to healthcare providers in England explicitly recognises that individuals can adopt approaches in mid-life, such as reducing alcohol consumption, stopping smoking, being more active, and adopting a healthier diet, in order to delay or prevent the onset of dementia and disability in later

97 See <www.dementiastatistics.org/statistics-about-dementia/prevalence $>$.

98 Ibid.

99 Ibid.

100 See <www.who.int/news-room/fact-sheets/detail/dementia>.

101 Elissa L Ash, 'What is Dementia?' in Charles Foster, Jonathan Herring and Israel Doron (eds), The Law and Ethics of Dementia (Hart 2018).

102 (APA 2000) and (WHO 1992).

103 Amos D Korczyn and Veronika Vakhapova, 'Can Dementia be Prevented?' in Foster at al (n 101).

104 See <www.dementiastatistics.org/statistics/attitudes-to-dementia>.

105 See, for example, Hui-Xin Wang, Weili Xu and Jin-Jing Pei, 'Leisure Activities, Cognition and Dementia' (2012) 1822(3) Biochimica et Biophyscia Acta (BBA) - Molecular Basis of Disease, 482-91; Joe Verghese et al, 'Leisure Activities and the Risk of Dementia in the Elderly' (2003) 348 New England Journal of Medicine 2508-16; Colette Fabrigoule et al, 'Social and Leisure Activities and Risk of Dementia: A Prospective Longitudinal Study' (1995) 43(5) Journal of the American Geriatrics Society 485-90. 
life. ${ }^{106}$ And Public Health England's five-year strategy in 2014 identified reducing the risk, incidence and prevalence of dementia in people aged $65-75$ as one of its key priorities. ${ }^{107}$

In accordance with the discussion above in section 3.1, public perceptions of dementia are a significant contributing factor for effective management and treatment. ${ }^{108}$ This is referred to as 'mental health literacy', ${ }^{109}$ and various studies from across the globe have demonstrated the correlation between public/lay beliefs concerning dementia, stereotyping and help-seeking. ${ }^{110}$ There is evidence to suggest that, despite increased awareness, many people still have relatively poor levels of knowledge about the causes, symptoms and treatments. ${ }^{111}$ Furthermore, people with the Alzheimer's disease 'label' report that they experience increased stigma. ${ }^{112}$

A report by the WHO and Alzheimer's International, entitled Dementia: A Public Health Priority, ${ }^{113}$ recognises that 'although dementia mainly affects older people, it is not a normal part of ageing', as it is a condition which develops, and is caused by several different factors and illnesses of the brain. Carers, relatives and persons with dementia have unique insights into their condition and life, and should be central to formulating policies, laws, and decision-making and services that relate to them. ${ }^{114}$ However, evidence suggests that many people with dementia either do not receive basic care to which they are entitled or are subjected to restraint and highly coercive care practices. ${ }^{115}$ As the WHO states:

It is widely recognized that people with dementia are frequently denied the basic rights and freedoms available to others. In many countries physical and chemical restraints are used extensively in aged-care facilities and acute-care settings, even when regulations are in place to uphold the rights of people to freedom and choice. The majority of people who are restrained have cognitive impairment. ${ }^{116}$

This clearly suggests a need for an appropriate and supportive legislative environment, based on human rights standards, as an important tool to promote the highest levels of

106 NICE Guideline [NG16], Dementia, Disability and Frailty in Later Life-Mid-life Approaches to Delay or Prevent Onset (NICE October 2015).

107 Public Health England, From Evidence into Action: Opportunities to Protect and Improve the Nation's Health (Public Health England, 23 October 2014).

108 Perla Werner, 'Common Perceptions of Dementia' in Foster et al (n 101).

109 Anthony F Jorm et al, "Mental Health Literacy": A Survey of the Public's Ability to Recognise Mental Disorders and their Beliefs about the Effectiveness of Treatment' (1997) 166 Medical Journal of Australia 182-6.

110 See, for example, W J Tan et al, 'The Lay Public's Understanding and Perception of Dementia in a Developing Asian Nation' (2012) 2 Dementia and Other Geriatric Cognitive Disorders 433-44; V G Wadley and W E Haley, 'Diagnostic Attributions Versus Labelling: Impact of Alzheimer's Disease and Major Depression Diagnoses on Emotions, Beliefs, and Helping Intentions of Family Members' (2001) 56(4) Journals of Gerontology 244-52; Monica Cations et al, 'What Does the General Public Understand about Prevention and Treatment of Dementia? A Systematic Review of Population Based Surveys' (2018) 13(4) PLoS ONE: see $<$ https://journals.plos.org/plosone/article?id=10.1371/journal.pone.0196085>.

111 John M Hudson et al, 'Beliefs about Alzheimer's Disease in Britain'(2012) 16(7) Aging and Mental Health 82835.

112 Wadley and Haley (n 110); Naheed Mukadam and Gill Livingston, 'Reducing the Stigma Associated with Dementia: Approaches and Goals,' (2012) 8 Aging Health 377-86.

113 (2012) see <http://apps.who.int/iris/bitstream/handle/10665/75263/9789241564458_eng.pdf;jsessionid= 6ACB2D62C2CDCE3A8567F0B0F68DAA49? sequence $=1>$.

114 Ibid 4.

115 See (n 100).

116 WHO/Alzheimer's International (n 4). 
care and service provision for people with dementia. In addition, we need to look at how appropriately law serves the needs of persons with dementia outside of institutional and acute-care situations.

Focusing on England, the government has attempted to address some of the deficits identified. At a policy level, the 2010-2015 Coalition government developed a dementia strategy with the aim of providing a framework for addressing health inequalities relating to dementia and dementia services. ${ }^{117}$ This was followed in 2015 by then Prime Minister David Cameron's Challenge on Dementia, with a vision for targeted action and implementation by 2020.118 The plan included training for NHS staff on dementia, meaningful care for everyone diagnosed with dementia, and equal access to diagnosis. The current Conservative government announced in May 2018 that it is reviewing the Challenge on Dementia plan to reflect on progress and what further action is needed to meet the objectives, ${ }^{119}$ as we are still a long way from realising many of the goals set out in the 2020 challenge. Successive governments' dementia policies have faced some criticism for not going far enough, ${ }^{120}$ and there are further concerns that dementia has not been included in the recent NHS spending priorities. ${ }^{121}$

Law is not being used to its full potential here. Existing legal responses to provide treatment and care in England are centred primarily on the MHA and Mental Capacity Act 2005 (MCA), which are highly responsive, protective and coercive; albeit, as noted above, the Care Act regulates social care in a community, as opposed to a healthcare, setting. The MHA, as explained above, is reactive. It is deeply paternalistic and takes little account of the views of the individual patient or family/carers. ${ }^{122}$ Notwithstanding its empowering aims and ethos, there are significant challenges to applying the MCA's determination of capacity and welfare approach to people with dementia. For instance, there are tensions in disentangling persons' past and present wishes (as required in application of the 'best interests' standard under s 4), and the capacity test is individualised - 'decision-specific' - and thereby focused heavily on immediate processes of cognition. ${ }^{123}$ It provides binary distinctions that are rooted in functional mental competences, and which are not suited to decision-making of persons with conditions such as dementia. As such, Mary Donnelly has argued that 'the law must address issues raised by dementia on their own terms and not simply as a subset of a broader capacity/incapacity agenda'. 124 In several respects, current regulatory frameworks in England are crude and inappropriate for individuals with dementia. ${ }^{125}$ They focus on

117 Living Well with Dementia: A National Dementia Strategy (Department of Health 2009) <https://assets.publishing.service.gov.uk/government/uploads/system/uploads/attachment_data/file/1682 20/dh_094051.pdf>.

118 Prime Minister's Challenge on Dementia - Delivering Major Improvements in Dementia Care and Research by 2015 (Department of Health March 2012).

119 See further House of Commons Library, Dementia: Policy, Services and Statistics (Briefing Paper 0700710 July 2018) 3.

120 See, for example, Ian Greaves and David Jolley, 'National Dementia Strategy: Well Intentioned - But How Well Founded and How Well Directed?' (2010) 60(572) British Journal of General Practice 193-8; 'Dementia Strategy Criticised by Alzheimer's Trust' The Guardian (London, 3 February 2009).

121 'Dementia is Conspicuously Absent from New NHS Priorities' (Alzheimer's Research UK Blog, 31 July 2018) $<$ www.dementiablog.org/dementia-is-conspicuously-absent-from-new-nhs-priorities>.

122 See, for example, Independent Review (n 53) 26-9.

123 See, for example, Jonathan Herring, 'Losing It? Losing What? The Law and Dementia' (2009) 21(1) Child and Family Law Quarterly 3-29.

124 Mary Donnelly, 'A Legal Overview’ in Foster et al (n 101) 279.

125 Ibid. 
reactive biomedical models and ignore social/external factors and determinants, as well as the need to promote individual agency within a broader, more relational 'community' framework. ${ }^{126}$ A broader-reaching network of supports and interventions that respect and honour persons' rights, as explained above, is what is required.

Investing in evidence-based public health measures and associated regulatory responses could have a measurable impact, as a recent Lancet Commission report on dementia in England has highlighted. ${ }^{127}$ It is imperative to act now in order to transform society and 'vastly improve living and dying'128 for individuals with dementia. As the WHO and Alzheimer's International recommend, we must develop responses across sectors and disciplines which maximise agency, as well as prevention and protection for individuals, families and communities:

It is essential that rights are recognized, respected and protected in order to empower people with dementia, those who support them and the community as a whole. An appropriate and supportive legislative environment is also required to ensure the highest quality of service provision to people with dementia and their caregivers. ${ }^{129}$

Such recognition of the need for a supportive legislative environment accords with our analysis in this paper. In Part 2, we demonstrated the inadequacies of the over-atomised individual of medical law, and indeed general conceptualisation around the figure of 'the (autonomous) patient'. In explaining these inadequacies, we noted the challenges rooted in relationality of persons, and the need to move within rights framings to more robust and realisable 'positive' rights. The consequent discussions in section 3, in particular on the need for real and practicable effect being given to the protection of socio-economic rights (as re-enforced through the CRPD), have shown why law is essential to providing the conditions for people's enjoyment of good mental health: political commitment is necessary, but alone demonstrably inadequate.

Legal frameworks that are truly empowering require to be able, in practice, actually to accommodate the nature of the persons that they govern: this is not just about conceptualising a 'patient' and will not adequately be provided without tests and standards that are fitting given the impact and effect of dementias. They equally must be able to accommodate the relevant social concerns, allowing for informal as well as formal provision of care, economic realities, and the roles and responsibilities of myriad public, private and community actors. The task is vast, and ambitious. If health law is to make the contributions that are required of it, it needs to match that ambition.

\section{Conclusions: public mental health law and the future of health law scholarship}

Health law as a field of study and of practice has grown enormously over the past decades. Looking towards the coming decades, we see necessary value in securing this expansion. Health lawyers are crucial partners in work across sectors, and in securing legal support and constraint on questions of policy, practice and personal health and wellbeing. It is essential, as explained in this paper, that we move beyond paradigms that emerged in medical law, or even healthcare law. We are interested in actors across society, and

126 Ibid. Cf also Camillia Kong, Mental Capacity in Relationship: Decision-making, Dialogue, and Autonomy (Cambridge University Press 2017).

127 Gill Livingston et al, 'Dementia Prevention, Intervention and Care' (2017) 390 The Lancet Commissions 2673-4. See also Vikram Patel et al, 'The Lancet Commission on Global Mental Health and Sustainable Development' (2018) 392; 10157 The Lancet 1553-98.

$128 \operatorname{Ibid} 2673$.

129 WHO/Alzheimer's International (n 4). 
empowering concepts of law that do not just protect narrow, 'negative' rights. We need to grasp legal levers that support positive claims to socio-economic goods. And in so doing, we need frameworks that provide normative as well as practical authority (and security) to such claims. Health law must be considered as more than holding strengths as a reactive or defensive force.

As an important component of this agenda, we have in this paper presented an account of public mental health law; an area whose time is now and which requires active, positive engagement between law and other fields. The vision that we have advocated for underscores the crucial role for human rights for academic and activist activities. We are witnessing a global crisis in mental health. Traditional responsive measures are not effective in combating it. We need to reinvigorate the debate, move to a new way of thinking, and put prevention of ill health and promotion of well-being at the heart of our response. Public mental health law will assist us to move towards that goal. And human rights can provide us with a universal and workable analytical framework to do so. As Gostin and Gable argue:

The various systems for the protection of human rights present the opportunity to provide tangible human rights protection for persons with mental disabilities at both the individual and population level ... Human rights are not a panacea for persons with mental disabilities. Nevertheless, more focused attention on the civil and political, as well as social and economic rights of this group is vitally important. ${ }^{130}$

Discourse around the right to health and ECHR rights will be crucial motivating factors. And the CRPD undoubtedly has a valuable role to play in shifting the paradigm and combating the underlying determinants of mental disability and ill health. The time is ripe for relevant stakeholders to explore the evidence base and prioritise mental health promotion and illness prevention. As the WHO has recognised in a report on Prevention of Mental Disorders: Effective Interventions and Policy Options:

Limitations on the basic human rights of vulnerable individuals and communities may act as powerful determinants of mental disorders. Hence it is not surprising that many of the effective preventive measures are harmonious with principles of social equity, equal opportunity and care of the most vulnerable groups in society. 131

The science of public mental health is well understood; the art, less so. ${ }^{132}$ We have explained here the foundations of law's contribution to debate and practice. This is an ambitious research agenda, and one whose practical importance cannot be overstated.

130 Lawrence O Gostin and Lance Gable, 'The Human Rights of Persons with Mental Disabilities: A Global Perspective on the Application of Human Rights Principles to Mental Health' (2004) 63 Maryland Law Review 20.

131 (WHO 2004).

132 Cf John Coggon, 'Law' in Sridhar Venkatapuram and Jo Bibby (eds), A Recipe for Action: Using Wider Evidence for a Healthier UK: A Collection of Essays Exploring Why We Need Trans-disciplinary Approaches to Improve the Public's Health (Health Foundation 2018). 